\title{
ARTICLE
}

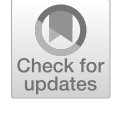

Cite as

Nano-Micro Lett.

(2021) 13:47

Received: 14 September 2020 Accepted: 19 November 2020 Published online: 4 January 2021 (C) The Author(s) 2021

\section{Hierarchical Magnetic Network Constructed by CoFe Nanoparticles Suspended Within "Tubes on Rods" Matrix Toward Enhanced Microwave Absorption}

\author{
Chunyang $\mathrm{Xu}^{1}$, Lei Wang ${ }^{1}, \mathrm{Xiao} \mathrm{Li}^{1}$, Xiang Qian ${ }^{1}$, Zhengchen $\mathrm{Wu}^{1}$, Wenbin You ${ }^{1}$, \\ Ke Pei ${ }^{1}$, Gang Qin ${ }^{1}$, Qingwen Zeng ${ }^{1}$, Ziqi Yang ${ }^{1}$, Chen Jin $^{1}$, Renchao Che ${ }^{1} \bowtie$
}

\section{HIGHLIGHTS}

- Three-dimension hierarchical core-shell $\mathrm{Mo}_{2} \mathrm{~N} @ \mathrm{CoFe} @ \mathrm{C} / \mathrm{CNT}$ composites were successfully constructed via a fast MOF-based ligand exchange strategy.

- Abundant magnetic CoFe nanoparticles suspended within "nanotubes on microrods" matrix exhibited strong magnetic loss capability, confirmed by off-axis electron holography.

- Hierarchical $\mathrm{Mo}_{2} \mathrm{~N} @ \mathrm{CoFe} @ \mathrm{C} / \mathrm{CNT}$ composites displayed remarkable microwave absorption value of - $53.5 \mathrm{~dB}$.

\begin{abstract}
Hierarchical magnetic-dielectric composites are promising functional materials with prospective applications in microwave absorption (MA) field. Herein, a three-dimension hierarchical "nanotubes on microrods," core-shell magnetic metal-carbon composite is rationally constructed for the first time via a fast metal-organic frameworksbased ligand exchange strategy followed by a carbonization treatment with melamine. Abundant magnetic $\mathrm{CoFe}$ nanoparticles are embedded within one-dimensional graphitized carbon/carbon nanotubes supported on micro-scale $\mathrm{Mo}_{2} \mathrm{~N}$ rod $\left(\mathrm{Mo}_{2} \mathrm{~N} @ \mathrm{CoFe} @ \mathrm{C} / \mathrm{CNT}\right)$, constructing a spe-

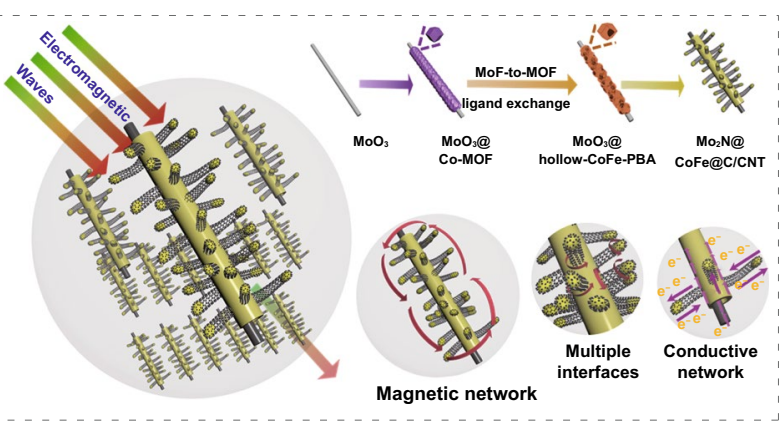
cial multi-dimension hierarchical MA material. Ligand exchange reaction is found to determine the formation of hierarchical magnetic-dielectric composite, which is assembled by dielectric $\mathrm{Mo}_{2} \mathrm{~N}$ as core and spatially dispersed CoFe nanoparticles within C/CNTs as shell. $\mathrm{Mo}_{2} \mathrm{~N} @ \mathrm{CoFe} @ \mathrm{C} / \mathrm{CNT}$ composites exhibit superior MA performance with maximum reflection loss of $-53.5 \mathrm{~dB}$ at $2 \mathrm{~mm}$ thickness and show a broad effective absorption bandwidth of 5.0 GHz. The $\mathrm{Mo}_{2} \mathrm{~N} @$ CoFe@C/CNT composites hold the following advantages: (1) hierarchical core-shell structure offers plentiful of heterojunction interfaces and triggers interfacial polarization, (2) unique electronic migration/hop paths in the graphitized $\mathrm{C} / \mathrm{CNTs}_{\mathrm{N}}$ and $\mathrm{Mo}_{2} \mathrm{~N}$ rod facilitate conductive loss, (3) highly dispersed magnetic CoFe nanoparticles within "tubes on rods" matrix build multi-scale magnetic coupling network and reinforce magnetic response capability, confirmed by the off-axis electron holography.
\end{abstract}

KEYWORDS Hierarchical core-shell MOF-based composites; CoFe nanoparticles; Magnetic network; Microwave absorption

Renchao Che, rcche@fudan.edu.cn

1 Laboratory of Advanced Materials, Department of Materials Science and Collaborative Innovation Center of Chemistry for Energy Materials (iChem), Fudan University, Shanghai 200438, People's Republic of China 


\section{Introduction}

Coming into the fifth-generation (5G) wireless communication systems, the increasing usage of diverse electronic productions has caused severe electromagnetic radiation pollution, which results in an urgent pursuit for high-performance microwave absorption (MA) materials [1-9]. Magnetic materials, including metals $(\mathrm{Co}, \mathrm{Ni}, \mathrm{Fe})$ and metallic alloys (FeCo, NiCo, etc.), are generally used as microwave absorbents due to strong magnetic loss ability [10-18]. However, practical applications of magnetic materials suffer from their inherent drawbacks: undesirable chemical stability, severe aggregation and inferior impedance matching [19-21]. To tackle these obstacles, two typical strategies have been commonly employed to shape MA properties. One is to decorate magnetic component with carbon materials to develop magnetic-dielectric system and thereby boost the MA performance by enhancing dielectric loss and improving impedance matching [22-31]. For example, Cao et al. designed Fe@NCNTs composite and showed MA performance of $-30.43 \mathrm{~dB}$ [32]. Shui et al. prepared CoFe/carbon fiber composite with high MA properties [13]. Tong et al. designed $\mathrm{Co} / \mathrm{C} /$ $\mathrm{Fe} / \mathrm{C}$ composite which exhibited significantly improved MA abilities [11]. The other is to construct hierarchicalstructured materials with well-designed nano-units, thus achieving high dispersion of magnetic particles and producing heterogeneous interface in multicomponent materials [33-37]. Among various hierarchical structures, the core-shell structures have attracted growing attention in the MA field [38-40] such as Co@ C microspheres [10], $\mathrm{Fe}_{3} \mathrm{O}_{4} / \mathrm{C}$ [41], $\mathrm{Co} @ \mathrm{CoO}$ [42], $\mathrm{Co}_{20} \mathrm{Ni}_{80} @ \mathrm{TiO}_{2}$ core-shell structure [43]. The delicately designed core-shell composites can satisfy magnetic and dielectric loss simultaneously resulting from synergistic effects of different components within both core and shell [44, 45]. Besides, large interspace and heterogeneous interface created by core-shell structure can further enhance polarization loss and strengthen multi-reflection process [37, 44, 46]. Particularly, hierarchical 1D units assembled core-shell composites exhibit remarkable performance in MA application [14, 47, 48]. For example, Che et al. designed hierarchically tubular C/Co composite with abundant 1D nanotubes and achieved highly uniform distribution of Co nanoparticles and outstanding MA performance [49]. Therefore, it is highly desirable to develop a facile and effective preparation strategy to construct magnetic metal-carbon composites with hierarchical core-shell structure.

Metal-organic frameworks (MOFs), with diverse microstructure and adjustable composition, have been widely utilized to construct various hierarchical composites [50-54]. MOF-derived materials demonstrate inherent advantages of abundant metal/carbon components, which endows them with great potential in MA application [40, 55-60]. For example, Ji et al. developed MOF-derived one-dimensional sponge-like metallic $\mathrm{Co}$ and $\mathrm{Co} / \mathrm{C}$ composites with strong magnetic loss [61]. Du et al. presented a MOFs-derived method to construct hollow $\mathrm{Co} / \mathrm{C}$ microspheres as microwave absorbents [62]. Zhao et al. prepared hierarchical $\mathrm{Fe}-\mathrm{Co} / \mathrm{N}$-doped carbon/rGO composites derived from Fe-doped Co-MOF [63]. However, direct transforming MOFs into microwave absorbents leads to a much lower ratio of metal nanoparticles and poor graphitization degree of carbon or CNTs, which is unfavorable to the attenuation of microwave. To tackle these problems, the MOF precursor can be further extended by transforming one kind of MOF into another via ion exchange reactions or ligand exchange reactions, introducing more magnetic metals and carbon components. For example, $\mathrm{Hu}$ et al. constructed hierarchical bimetallic $\mathrm{Co}_{2}\left[\mathrm{Fe}(\mathrm{CN})_{6}\right]$ hollow structure from a Co-MOF through ion exchange reactions [64]. This MOF-to-MOF strategy inspires us to construct bimetallic MOF-derived carbon-based absorbents with favorable hierarchical structure, which has rarely been reported in MA field.

Recently, transition metal molybdenum-based materials, such as $\mathrm{MoO}_{2}, \mathrm{Mo}_{2} \mathrm{C}, \mathrm{MoS}_{2}$ and $\mathrm{Mo}_{2} \mathrm{~N}$, have emerged as effective candidates in the field of electrocatalysis, lithium batteries and supercapacitors due to its low cost, high conductivity and chemical stability [65-72]. Such superior properties also make molybdenum compounds promising microwave absorbents. For example, owing to metalliclike conductivity of $\mathrm{MoO}_{2}$ materials, Huang et al. constructed C@ $\mathrm{MoO}_{2} / \mathrm{G}$ composites for efficient MA [73]. Du et al. fabricated ternary $\mathrm{Mo}_{2} \mathrm{C} / \mathrm{Co} / \mathrm{C}$ composites for MA [74] and Jin et al. prepared $\mathrm{MoS}_{2}$-NS with high dielectric properties and MA performances [75]. However, the work 
of employing $\mathrm{Mo}_{2} \mathrm{~N}$ as microwave absorbent has not been studied so far, although $\mathrm{Mo}_{2} \mathrm{~N}$ materials exhibit satisfied electrical conductivity displaying excellent performance in electrocatalysis and supercapacitors [66, 69]. Therefore, compositing molybdenum compounds into metal-carbon absorbents with designed hierarchical structure is expected to achieve first-rate MA performance.

Herein, for the first time, a 3D hierarchical "nanotubes on microrods" core-shell composite of magnetic CoFe nanoparticles suspended within one-dimensional graphitized $\mathrm{C} / \mathrm{CNT}$ s supported on $\mathrm{Mo}_{2} \mathrm{~N}$ rod $\left(\mathrm{Mo}_{2} \mathrm{~N} @ \mathrm{CoFe} @ \mathrm{C} / \mathrm{CNT}\right)$ is successfully achieved through a fast MOF-based ligand exchange strategy. The intermediate product of $\mathrm{MoO}_{3} @$ hollow-CoFe-PBA composite plays an important role in not only providing $\mathrm{Fe}$ source for the growth of $\mathrm{CoFe}$ alloy and C/CNTs but also constructing hierarchical core-shell structure in final composite, thus achieving highly dispersive distribution of magnetic particles. The unique $\mathrm{Mo}_{2} \mathrm{~N} @$ $\mathrm{CoFe} @ \mathrm{C} / \mathrm{CNT}$ composite holds the dielectric $\mathrm{Mo}_{2} \mathrm{~N}$ as core and magnetic CoFe nanoparticles embedded C/CNTs as shell. Such 3D hierarchical magnetic network assembled by $\mathrm{CoFe}$ nanoparticles suspended within "tubes on rods" matrix demonstrates strong magnetic loss capability, which can be verified by off-axis electron holography. Besides, numerous $\mathrm{Mo}_{2} \mathrm{~N}$ rods and graphitized CNTs in the composite constitute dual conductive network to facilitate conductive loss. Moreover, large interfaces in hierarchical core-shell structure can trigger intensive polarization loss. Our hierarchical $\mathrm{Mo}_{2} \mathrm{~N} @ \mathrm{CoFe} @ \mathrm{C} / \mathrm{CNT}$ composite demonstrates superior MA performance with maximum reflection loss value of $-53.5 \mathrm{~dB}$ at the thickness of only $2 \mathrm{~mm}$ thickness and the effective absorption bandwidth can reach 5.0 GHz. Therefore, the presented fast MOF-based ligand exchange strategy provides an effective method to fabricate multicomponent absorbents with well-controlled hierarchical structure for achieving excellent MA properties.

\section{Experimental Section}

\subsection{Materials}

All chemicals used were of analytical grade and were used directly without further purification. All chemicals were purchased from Sinopharm Chemical Reagent Co., Ltd.

\subsection{Synthesis of $\mathrm{MoO}_{3}$}

In a typical synthesis, $0.5793 \mathrm{~g}$ ammonium molybdate tetrahydrate was dissolved in $30 \mathrm{~mL}$ of deionized (DI) water; then, $2.5 \mathrm{~mL}$ of $\mathrm{HNO}_{3}$ was added. The solution was kept stirring for $10 \mathrm{~min}$, then transferred into a Teflon-lined stainless autoclave $(50 \mathrm{~mL})$ and kept at $180{ }^{\circ} \mathrm{C}$ for $12 \mathrm{~h}$. When the temperature of Teflon-lined stainless autoclave was cooled naturally, the precipitate was collected and washed repeatedly with DI water for at least three times before drying at $70{ }^{\circ} \mathrm{C}$.

\subsection{Synthesis of $\mathrm{MoO}_{3} @ \mathrm{Co}-\mathrm{MOF}$}

First, the solution A was prepared by $50 \mathrm{mg}$ of $\mathrm{MoO}_{3}$ and $0.582 \mathrm{~g} \mathrm{CoNO}_{3} \cdot 6 \mathrm{H}_{2} \mathrm{O}$ were dissolved in $20 \mathrm{~mL}$ of methanol. Then solution $\mathrm{B}$ was prepared by dispersing $1.3132 \mathrm{~g}$ of 2-methylimidazole in $20 \mathrm{~mL}$ of methanol. The solution $\mathrm{B}$ was added into solution A under stirring and kept stirring for $5 \mathrm{~min}$ then aged for $20 \mathrm{~min}$ at room temperature. The precipitate was collected and washed with ethanol for at least three times and dried at $70{ }^{\circ} \mathrm{C}$.

\subsection{Synthesis of $\mathrm{MoO}_{3} @$ hollow-CoFe-PBA}

$40 \mathrm{mg}$ of $\mathrm{MoO}_{3} @ \mathrm{Co}-\mathrm{MOF}$ was dissolved in $10 \mathrm{~mL}$ ethanol to get solution C. $40 \mathrm{mg}$ of $\mathrm{K}_{3}\left[\mathrm{Fe}(\mathrm{CN})_{6}\right]$ was dissolved in $20 \mathrm{~mL}$ DI water and $20 \mathrm{~mL}$ ethanol to get solution $\mathrm{D}$. Then solution D was poured into solution $\mathrm{C}$ under stirring and kept stirring for $5 \mathrm{~min}$. The precipitate was collected and washed with DI water and dried at $70{ }^{\circ} \mathrm{C}$.

\subsection{Synthesis of $\mathrm{Mo}_{2} \mathrm{~N} @ \mathrm{CoFe} @ \mathrm{C} / \mathrm{CNT}$}

In a typical synthesis, $0.1 \mathrm{~g}$ of as-prepared $\mathrm{MoO}_{3} @$ hollowCoFe-PBA and $0.5 \mathrm{~g}$ of melamine were placed separately in a quartz boat where the melamine was placed at upstream side of the furnace. The furnace was heated to $600{ }^{\circ} \mathrm{C}$ at a rate of $2{ }^{\circ} \mathrm{C} \mathrm{min}^{-1}$ for $4 \mathrm{~h}$ under a hydrogen/argon atmosphere. Finally, $\mathrm{Mo}_{2} \mathrm{~N} @ \mathrm{CoFe} @ \mathrm{C} / \mathrm{CNT}$ composite was obtained after cooling down to ambient temperature. 


\subsection{Synthesis of $\mathrm{Mo}_{2} \mathrm{~N}$ and $\mathrm{Mo}_{2} \mathrm{~N} @ \mathrm{Co} / \mathrm{CNT}$}

For comparison, $\mathrm{Mo}_{2} \mathrm{~N}$ and $\mathrm{Mo}_{2} \mathrm{~N} @ \mathrm{Co} / \mathrm{CNT}$ were synthesized by calcining the $\mathrm{MoO}_{3}$ and $\mathrm{MoO}_{3} @ \mathrm{Co}-\mathrm{MOF}$ with melamine, respectively.

\subsection{Microwave Absorption Measurements}

The measured samples were first prepared by adding the absorbents (20 wt \%) into molten paraffin and uniformly mixing them, followed by modeling into a coaxial ring with the outer diameter of $7.0 \mathrm{~mm}$ and inner diameter of $3.0 \mathrm{~mm}$. Electromagnetic parameters (complex permittivity and complex permeability) were measured by a N5230C vector network analyzer over the range of 2-18 GHz. The reflection loss values were calculated based on the transmission line theory:

$Z_{\text {in }}=\sqrt{\mu_{r} / \varepsilon_{r} \tanh \left|-j(2 \pi f d / c) \sqrt{\varepsilon_{r} \mu_{r}}\right|}$

$\mathrm{RL}(\mathrm{dB})=-20 \log \left|Z_{\text {in }}-1 / Z_{\text {in }}+1\right|$

where $\varepsilon_{r}$ and $\mu_{r}$ are the complex permittivity $\left(\varepsilon_{r}=\varepsilon^{\prime}-j \varepsilon^{\prime \prime}\right)$ and permeability $\left(\mu_{r}=\mu^{\prime}-j \mu^{\prime \prime}\right)$, respectively, $f$ is the frequency of microwave, $c$ is the velocity of light, $d$ is the thickness, and $Z_{\text {in }}$ is the normalized input impedance of the sample.

\subsection{Characterizations}

The crystalline phase and purity of the products was analyzed by powder X-ray diffraction (XRD, Bruker, D8-Advance X-ray diffractometer, Germany) using
$\mathrm{Ni}$-filtered $\mathrm{Cu}$ Ka radiation. The morphology and structure of the products were examined by a field-emission scanning electron microscopy (SEM) on a Hitachi S-4800 with an accelerating voltage of $5 \mathrm{kV}$ and a field-emission transmission electron microscope (TEM, JEOL, JEM-2100F, $200 \mathrm{kV}$ ). The Raman spectra were acquired with a Renishaw Invia spectrometer using a $514 \mathrm{~nm}$ laser excitation. X-ray photoelectron spectroscopy (XPS) spectra were obtained on an ESCALab MKII X-ray photoelectron spectrometer using Al K $\alpha$ X-ray as the excitation source. The hysteresis loops were performed with a superconducting quantum interference device (MPMS(SQUID) VSM) magnetometer (Quantum Design Company).

\section{Results and Discussion}

\subsection{Fabrication and Characterization of $\mathrm{Mo}_{2} \mathrm{~N} @$ CoFe@C/CNT Composites}

The synthesis of the hierarchical $\mathrm{Mo}_{2} \mathrm{~N} @ \mathrm{CoFe} @ \mathrm{C} / \mathrm{CNT}$ core-shell structure is illustrated in Fig. 1. First, the CoMOF is uniformly grown on $\mathrm{MoO}_{3}$ rod to form $\mathrm{MoO}_{3} @$ Co-MOF structure. Second, through a fast ligand exchange reaction with $\mathrm{K}_{3}\left[\mathrm{Fe}(\mathrm{CN})_{6}\right]$ in $5 \mathrm{~min}$ at room temperature, $\mathrm{MoO}_{3} @ \mathrm{Co}-\mathrm{MOF}$ structure is in situ converted into $\mathrm{MoO}_{3} @$ hollow-CoFe-PBA core-shell composite. Followed by the carbonization of $\mathrm{MoO}_{3} @$ hollow-CoFe-PBA with melamine, the inner $\mathrm{MoO}_{3}$ is transformed into $\mathrm{Mo}_{2} \mathrm{~N}$ rod and the outer hollow-CoFe-PBA turn into the CoFe@C/ CNTs architecture, where thermally reduced $\mathrm{CoFe}$ nanoparticles could catalyze the growth of graphitic carbon and CNTs with melamine as carbon source. Finally, the hierarchical $\mathrm{Mo}_{2} \mathrm{~N} @ \mathrm{CoFe} @ \mathrm{C} / \mathrm{CNT}$ composite with "tubes on rods" structure is successfully obtained. Moreover, through fast ligand exchange reaction, the intermediate product

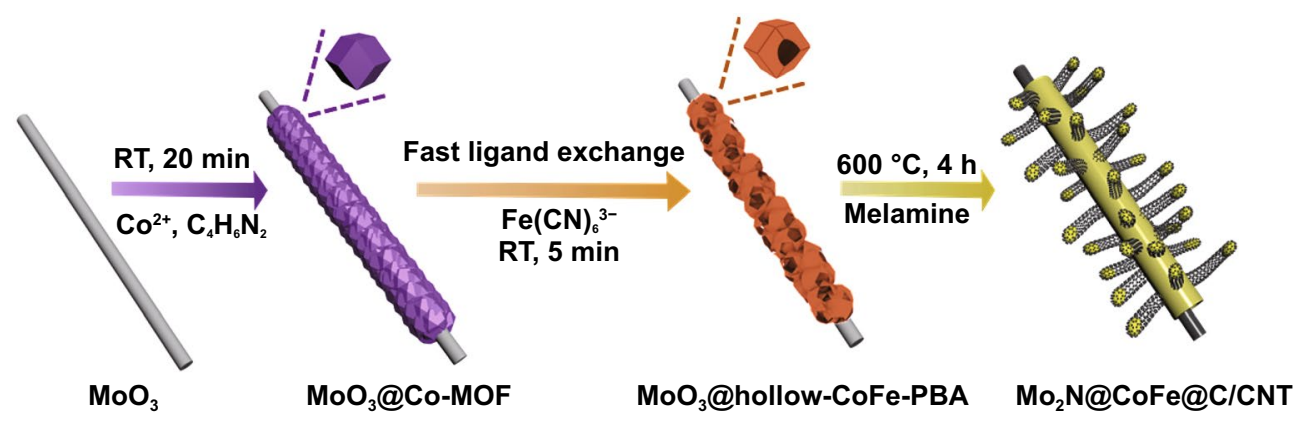

Fig. 1 Schematic process of the fast MOF-based ligand exchange strategy for construction of 3D hierarchical Mo $\mathrm{M}_{2} \mathrm{~N} @ \mathrm{CoFe} @ \mathrm{C} / \mathrm{CNT}$ composites 
of $\mathrm{MoO}_{3} @$ hollow-CoFe-PBA core-shell structure plays a critical role in the formation of hierarchical $\mathrm{Mo}_{2} \mathrm{~N} @$ $\mathrm{CoFe} @ \mathrm{C} / \mathrm{CNT}$ composite, which will be explained in the following discussion.

As displayed in Fig. S1, as-prepared uniform $\mathrm{MoO}_{3}$ rods demonstrate smooth surface and high phase purity. Then $\mathrm{MoO}_{3}$ rods are covered with Co-MOF to form $\mathrm{MoO}_{3} @$ Co-MOF structure. The SEM images reveal that the surface of $\mathrm{MoO}_{3}$ rods becomes rough (Fig. 2a). The core of $\mathrm{MoO}_{3}$ and shell of Co-MOF can be clearly observed in TEM images (Fig. 2b, c). And both diffraction peaks of $\mathrm{MoO}_{3}$ and $\mathrm{Co}-\mathrm{MOF}$ are well detected in XRD pattern (Fig. S2), indicating that Co-MOF is successfully grown on the $\mathrm{MoO}_{3}$ rods. To construct hollow CoFe-PBA on the $\mathrm{MoO}_{3}$ rods, the $\mathrm{MoO}_{3} @ \mathrm{Co}-\mathrm{MOF}$ samples are kept in $\mathrm{K}_{3}\left[\mathrm{Fe}(\mathrm{CN})_{6}\right]$ solution and stirred for just $5 \mathrm{~min}$ at room temperature to allow the ligand exchange reaction to prepare $\mathrm{MoO}_{3} @$ hollow-CoFe-PBA structure. Firstly, the $\mathrm{MoO}_{3} @ \mathrm{Co}-\mathrm{MOF}$ will slowly decompose in water/ethanol to release $\mathrm{Co}^{2+}$ ions. Then the $\left[\mathrm{Fe}(\mathrm{CN})_{6}\right]^{3-}$ ions are injected into the reaction solution. The released $\mathrm{Co}^{2+}$ ions can interact with $\left[\mathrm{Fe}(\mathrm{CN})_{6}\right]^{3-}$ ions to generate $\mathrm{CoFe}-\mathrm{PBA}$ shell around the framework of the precursors (Co-MOF). Finally, the solid Co-MOF shell is completely converted into hollow CoFe-PBA, and $\mathrm{MoO}_{3} @$ hollow-CoFe-PBA core-shell composites are obtained. As displayed in
Fig. 2d, the rather rough CoFe-PBA is grown on the $\mathrm{MoO}_{3}$ rods and some holes can be seen on the surface (as displayed in the yellow circles of Fig. 2d). Such unique shell of hollow CoFe-PBA can be further confirmed by TEM images. In Fig. 2e, f, the as-prepared $\mathrm{MoO}_{3} @$ hollow$\mathrm{CoFe}-\mathrm{PBA}$ structure is consisted of the nanocage-assembled CoFe-PBA shell and the $\mathrm{MoO}_{3}$ core. XRD result also demonstrates that the sample is composed of $\mathrm{MoO}_{3}$ and $\mathrm{Co}_{2}\left[\mathrm{Fe}(\mathrm{CN})_{6}\right]$ (Fig. S3) [64]. Such core-shell of $\mathrm{MoO}_{3} @$ hollow-CoFe-PBA composite plays a significant role not only in providing the $\mathrm{Fe}$ source for the growth of $\mathrm{CoFe}$ alloys and CNTs but also in constructing the core-shell structure in the final multicomponent products. Subsequently, the $\mathrm{MoO}_{3} @$ hollow-CoFe-PBA composite is converted into $\mathrm{Mo}_{2} \mathrm{~N} @ \mathrm{CoFe} @ \mathrm{C} / \mathrm{CNT}$ core-shell structure through the carbonization with melamine. For comparison, $\mathrm{Mo}_{2} \mathrm{~N}$ rod and $\mathrm{Mo}_{2} \mathrm{~N} @ \mathrm{Co} / \mathrm{CNT}$ samples are also synthesized by calcining the $\mathrm{MoO}_{3}$ and $\mathrm{MoO}_{3} @ \mathrm{Co}-\mathrm{MOF}$ composite with melamine, respectively.

The chemical compositions of $\mathrm{Mo}_{2} \mathrm{~N}$ rod, $\mathrm{Mo}_{2} \mathrm{~N} @$ $\mathrm{Co} / \mathrm{CNT}$, and $\mathrm{Mo}_{2} \mathrm{~N} @ \mathrm{CoFe} @ \mathrm{C} / \mathrm{CNT}$ composites are measured by XRD, Raman and XPS techniques. As displayed in Fig. $3 \mathrm{a}$, the diffraction peaks of $\mathrm{Mo}_{2} \mathrm{~N}$ rods are in accordance with reflections of molybdenum nitride $\left(\mathrm{Mo}_{2} \mathrm{~N}\right.$, JCPDS No. 25-1366) while the $\mathrm{Mo}_{2} \mathrm{~N} @ \mathrm{Co} /$ CNT samples exhibit diffraction peaks of both $\mathrm{Mo}_{2} \mathrm{~N}$ and
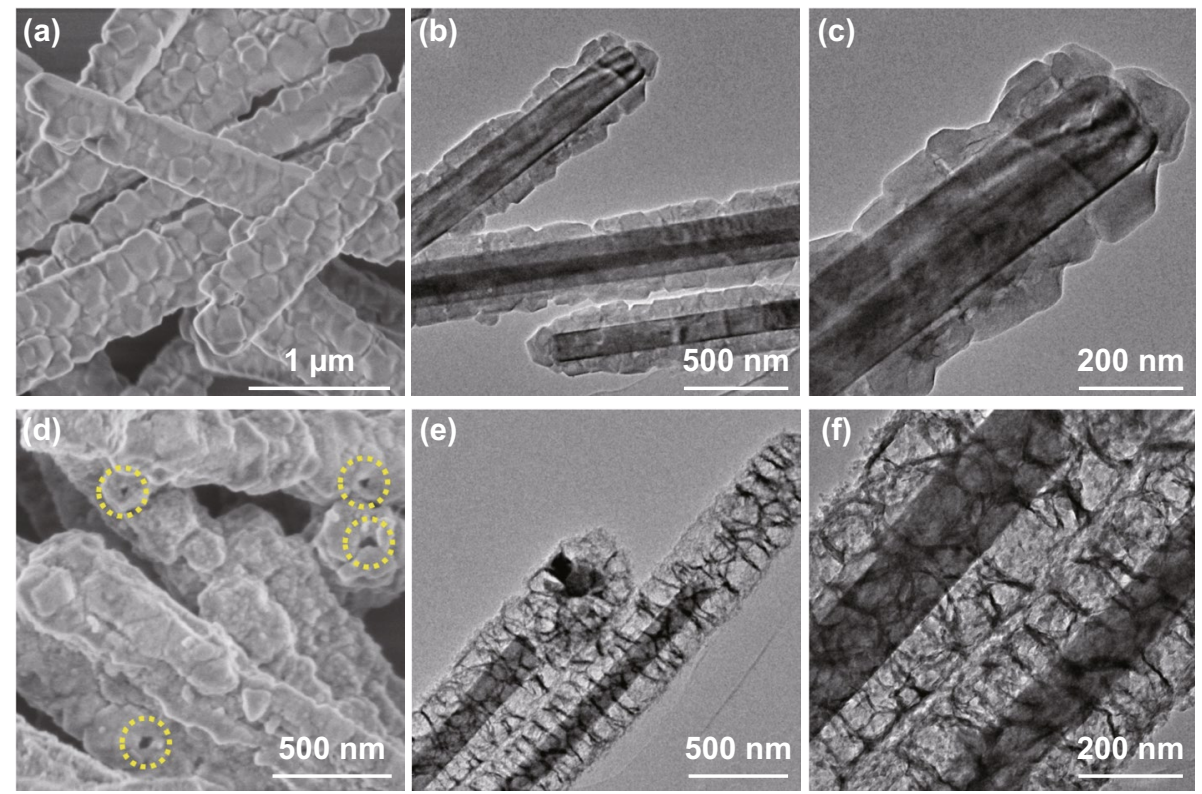

Fig. 2 a SEM, b, c TEM images of $\mathrm{MoO}_{3} @ \mathrm{Co}-\mathrm{MOF}, \mathbf{d}$ SEM, e, $\mathbf{f}$ TEM images of $\mathrm{MoO}_{3} @$ hollow-CoFe-PBA composites 

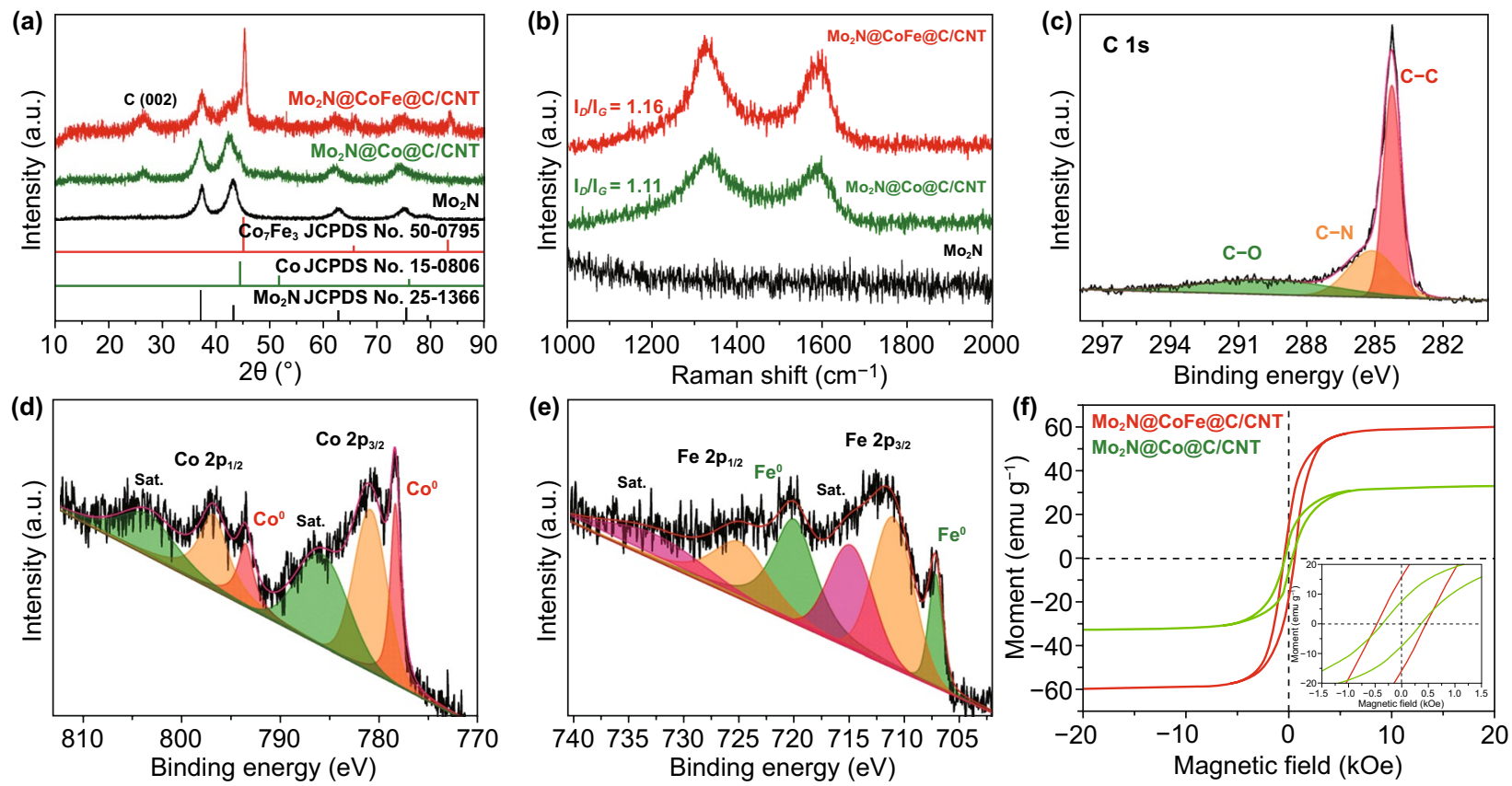

Fig. 3 a XRD patterns, b Raman spectra of as-prepared $\mathrm{Mo}_{2} \mathrm{~N}, \mathrm{Mo}_{2} \mathrm{~N} @ \mathrm{Co} / \mathrm{CNT}$ and $\mathrm{Mo}_{2} \mathrm{~N} @ \mathrm{CoFe} @ \mathrm{C} / \mathrm{CNT}$. High resolution XPS spectra of c $\mathrm{C} 1 s, \mathbf{d} \mathrm{Co} 2 p$, and $\mathbf{e} \mathrm{Fe} 2 p$ for $\mathrm{Mo}_{2} \mathrm{~N} @ \mathrm{CoFe} @ \mathrm{C} / \mathrm{CNT}$ composite. f hysteresis loops of $\mathrm{Mo}_{2} \mathrm{~N} @ \mathrm{Co} / \mathrm{CNT}$ and $\mathrm{Mo}_{2} \mathrm{~N} @ \mathrm{CoFe} @ \mathrm{C} / \mathrm{CNT}$ composites

cubic cobalt (JPCDS No. 15-0806). In the XRD pattern of $\mathrm{Mo}_{2} \mathrm{~N} @ \mathrm{CoFe} @ \mathrm{C} / \mathrm{CNT}$ composites, apart from characteristic peaks of $\mathrm{Mo}_{2} \mathrm{~N}$, a diffraction peak at $26.1^{\circ}$ can be observed clearly, attributing to the (002) plane of the graphitic carbon. Other peaks at around $45.2^{\circ}, 65.8^{\circ}$, and $83.3^{\circ}$ match well with diffractions of the cubic cobalt iron (JPCDS No. 50-0795). Above-mentioned XRD results demonstrate that the $\mathrm{Mo}_{2} \mathrm{~N} @ \mathrm{CoFe} @ \mathrm{C} / \mathrm{CNT}$ composite is consisted of $\mathrm{Mo}_{2} \mathrm{~N}, \mathrm{CoFe}$ alloy and graphitic carbon. To reveal the graphitic feature and structural defects of as-prepared samples, Raman spectra are conducted. In Fig. 3b, the $\mathrm{Mo}_{2} \mathrm{~N} @ \mathrm{CoFe} @ \mathrm{C} / \mathrm{CNT}$ composite exhibits the highest $I_{\mathrm{D}} / I_{\mathrm{G}}$ value of 1.16 because a great number of defects are produced in such core-shell structure. The value of $I_{\mathrm{D}} / I_{\mathrm{G}}$ is increased with more CNTs catalyzed by the $\mathrm{CoFe}$ alloy compared with less graphitic carbon by single metal $\mathrm{Co}$ in $\mathrm{Mo}_{2} \mathrm{~N} @ \mathrm{Co} / \mathrm{CNT}$ sample, which could promote the electronic transportation ability. Chemical valence states of $\mathrm{Mo}_{2} \mathrm{~N} @ \mathrm{CoFe} @ \mathrm{C} / \mathrm{CNT}$ are examined via XPS technique. In Fig. 3c, three peaks of $\mathrm{C} 1 s$ spectrum correspond to the $\mathrm{C}-\mathrm{C}(284.28 \mathrm{eV}), \mathrm{C}-\mathrm{N}(285.16 \mathrm{eV})$ and $\mathrm{C}-\mathrm{O}(189.73 \mathrm{eV})$ [76]. In the Co $2 p$ spectrum, peaks at 778.32 and $793.44 \mathrm{eV}$ are ascribed to $\mathrm{Co}^{0}$ in $\mathrm{Co} 2 p_{3 / 2}$ and $\mathrm{Co} 2 p_{1 / 2}$ and peaks at 780.82 and $796.67 \mathrm{eV}$ belong to $\mathrm{Co}^{2+}$ species. In Fig. 3e, the Fe $2 p$ spectrum can be decomposed into two peaks of $707.22 \mathrm{eV}$ for $\mathrm{Fe}^{0} 2 p_{3 / 2}$ and $719.97 \mathrm{eV}$ for $\mathrm{Fe}^{0} 2 p_{1 / 2}$ and other two peaks of 711.06 and $724.85 \mathrm{eV}$ for $\mathrm{Fe}^{2+} 2 p_{3 / 2}$ and $2 p_{1 / 2}$, respectively [63, 77-79]. The bimetal $\mathrm{CoFe}$ with multiple valency in $\mathrm{Mo}_{2} \mathrm{~N} @ \mathrm{CoFe} @ \mathrm{C} / \mathrm{CNT}$ sample could result in higher saturation magnetization. As shown in Fig. 3f, the saturation magnetization $(M \mathrm{~s})$ value of $\mathrm{Mo}_{2} \mathrm{~N} @ \mathrm{CoFe} @ \mathrm{C} / \mathrm{CNT}$ is $59.6 \mathrm{emu} \mathrm{g}{ }^{-1}$, which is higher than that of $\mathrm{Mo}_{2} \mathrm{~N} @ \mathrm{Co} / \mathrm{CNT}$ sample. And the coercivity value is $449.6 \mathrm{Oe}$ for $\mathrm{Mo}_{2} \mathrm{~N} @ \mathrm{CoFe} @ \mathrm{C} / \mathrm{CNT}$ composite. Such high saturation magnetization and low coercivity of $\mathrm{Mo}_{2} \mathrm{~N} @ \mathrm{CoFe} @ \mathrm{C} / \mathrm{CNT}$ hierarchical structure could boost magnetic storage and reinforce magnetic loss, further promoting MA performance $[57,80]$.

The morphology and structure of $\mathrm{Mo}_{2} \mathrm{~N}$ rod, $\mathrm{Mo}_{2} \mathrm{~N} @$ $\mathrm{Co} / \mathrm{CNT}$ and $\mathrm{Mo}_{2} \mathrm{~N} @ \mathrm{CoFe} @ \mathrm{C} / \mathrm{CNT}$ core-shell composites are further performed with SEM and TEM images. As displayed in Fig. 4, a large number of CNTs are produced and deposited on the core of $\mathrm{Mo}_{2} \mathrm{~N}$ rod which can be clearly observed in Fig. $4 \mathrm{a}-\mathrm{c}$ with yellow arrows. In the following TEM images, the rod-like core is seen and wrapped by outer shell of numerous CNTs. Particularly, the obvious void exists between the shell and core (Fig. 4d-f) and the CNTs are not directly grown on the $\mathrm{Mo}_{2} \mathrm{~N}$ rod but supported by the 

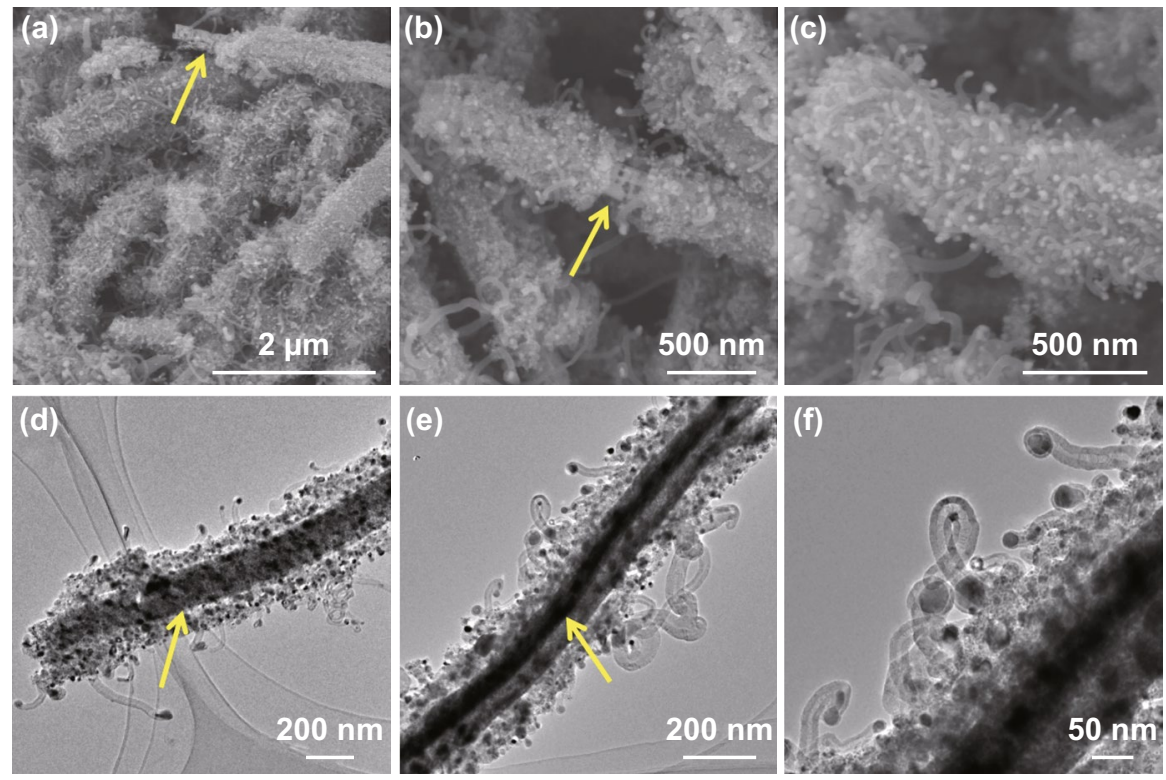

Fig. 4 a-c SEM, $\mathbf{d}-\mathbf{f}$ TEM images of $\mathrm{Mo}_{2} \mathrm{~N} @ \mathrm{CoFe} @ \mathrm{C} / \mathrm{CNT}$ composites

shell of CoFe alloy embedded graphitic carbon layers. Such uniquely hierarchical $\mathrm{Mo}_{2} \mathrm{~N} @ \mathrm{CoFe} @ \mathrm{C} / \mathrm{CNT}$ core-shell structure is reported for the first time and can be further confirmed by the magnified TEM and HRTEM images. Abundant CNTs can be seen and on the top of each CNT is encapsulated metal nanoparticles, which are wrapped by numbers of graphitic carbon layers (Fig. 5a-d). In Fig. 5e, the HRTEM image obtained from the shell of such $\mathrm{Mo}_{2} \mathrm{~N} @$
CoFe@C/CNT structure (as marked in Fig. 5a with yellow square) demonstrates that the interplanar spacing of $0.20 \mathrm{~nm}$ can correspond to the (110) plane of CoFe alloy and $0.34 \mathrm{~nm}$ to the (002) plane of graphitic carbon, which convincingly confirms such unique shell of CoFe nanoparticles embedded graphitic carbon. The corresponding selected area electron diffraction pattern displays a series of diffraction rings which can be well indexed to diffraction planes of crystalline $\mathrm{Mo}_{2} \mathrm{~N}$
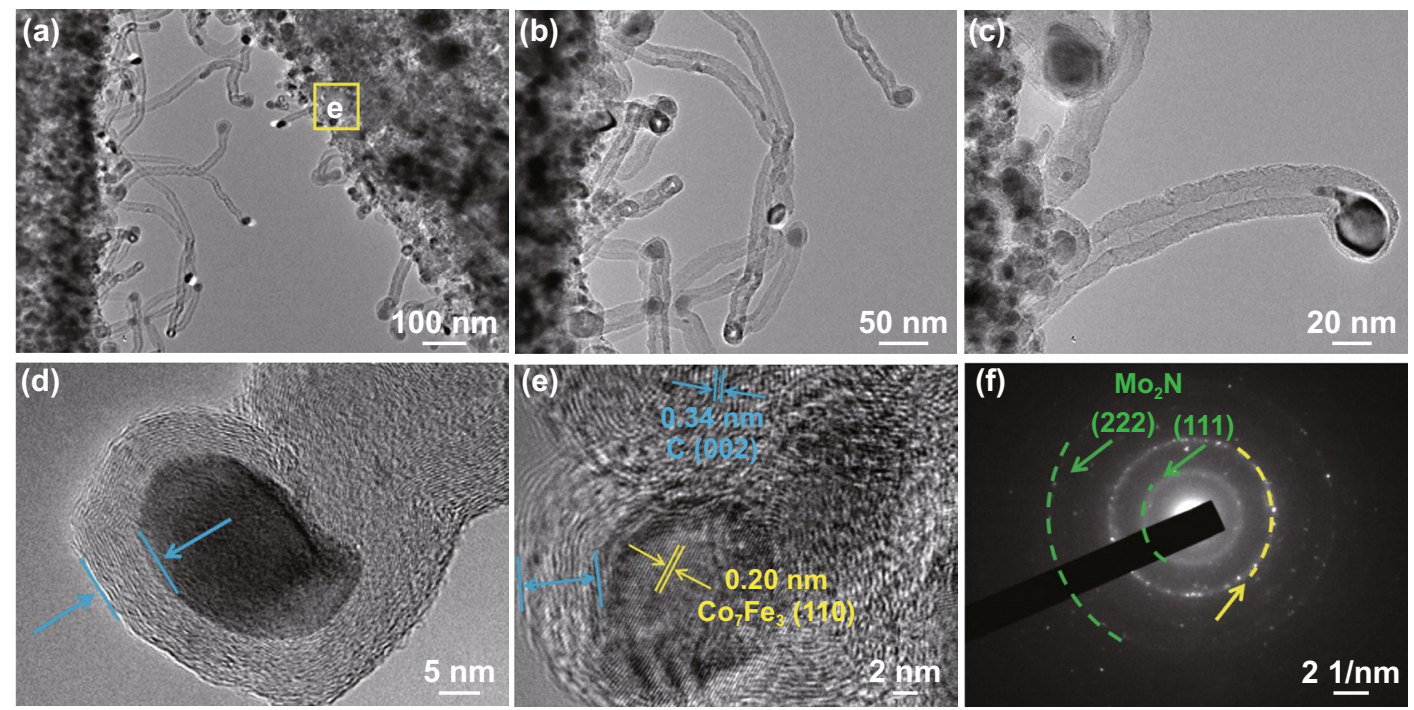

Fig. 5 a-c The magnified TEM, d-e HRTEM images and $\mathbf{f}$ corresponding selected area electron diffraction of $\mathrm{Mo}_{2} \mathrm{~N} @ \mathrm{CoFe} @ \mathrm{C} / \mathrm{CNT}$ composites 
and CoFe alloy (Fig. 5f). Clearly, based on the above results of morphology and composition, hierarchical $\mathrm{Mo}_{2} \mathrm{~N} @$ CoFe@C/CNT "tubes on rods" architecture is successfully synthesized through a fast MOF-based ligand exchange strategy. In the calcinating process of $\mathrm{MoO}_{3} @$ hollow-CoFe-PBA composite with melamine, the $\mathrm{MoO}_{3}$ is converted into the core of $\mathrm{Mo}_{2} \mathrm{~N}$ rod and hollow-CoFe-PBA is transformed into the shell of CoFe alloy embedded C/CNTs with thermally reduced $\mathrm{CoFe}$ nanoparticles as catalysts and melamine as carbon source. For comparison, $\mathrm{Mo}_{2} \mathrm{~N} @ \mathrm{Co} / \mathrm{CNT}$ sample is obtained by directly annealing $\mathrm{MoO}_{3} @ \mathrm{Co}-\mathrm{MOF}$ composite with melamine. As shown in Fig. S4, the $\mathrm{Mo}_{2} \mathrm{~N} @ \mathrm{Co} / \mathrm{CNT}$ composites maintain the rod structure but only few of CNTs are observed on the surface of $\mathrm{Mo}_{2} \mathrm{~N}$ rod without the shell of metal-embedded graphitic carbon framework. This evidence suggests that single Co nanoparticles could not effectively catalyze the growth of CNTs. Obviously, $\mathrm{MoO}_{3} @$ hollowCoFe-PBA structure constructed by ligand exchange reaction critically determines the formation of $\mathrm{CoFe}$ nanoparticles, graphitic C/CNTs and hierarchical core-shell structure. Rod-like $\mathrm{Mo}_{2} \mathrm{~N}$ are prepared through annealing $\mathrm{MoO}_{3}$ rods with melamine, which displays uniformly smooth rod structure (Fig. S5). Remarkably, as-prepared hierarchical $\mathrm{Mo}_{2} \mathrm{~N} @$ $\mathrm{CoFe} @ \mathrm{C} / \mathrm{CNT}$ can be considered as both distinct conductive structure and magnetic network, which hold great potential to achieve superior MA ability.

\subsection{Electromagnetic Parameters Analysis and Microwave Absorption Ability}

Related electromagnetic parameters of as-prepared $\mathrm{Mo}_{2} \mathrm{~N} @$ $\mathrm{CoFe} @ \mathrm{C} / \mathrm{CNT}, \mathrm{Mo}_{2} \mathrm{~N} @ \mathrm{Co} / \mathrm{CNT}$ and $\mathrm{Mo}_{2} \mathrm{~N}$ samples are investigated to reveal the impacts of structure and composition on the MA performance. Generally, MA properties are highly determined by the complex permittivity and complex permeability of materials. It is acknowledged that the real parts of complex permittivity $\left(\varepsilon^{\prime}\right)$ and complex permeability $\left(\mu^{\prime}\right)$ indicate the capability of storing electromagnetic energy, while the imaginary parts $\left(\varepsilon^{\prime \prime}, \mu^{\prime \prime}\right)$ imply the ability to loss electromagnetic energy. As shown in Fig. S8, the pure $\mathrm{Mo}_{2} \mathrm{~N}$ sample displays real permittivity $\left(\varepsilon^{\prime}\right)$ ranging from 12.06 to 10.92 , suggesting the $\mathrm{Mo}_{2} \mathrm{~N}$ is a better dielectric material. And the $\varepsilon^{\prime}$ values of $\mathrm{Mo}_{2} \mathrm{~N} @ \mathrm{Co} / \mathrm{CNT}$ samples rise obviously from 19.40 to 12.76 due to the introduction of conductive CNTs. When more CoFe alloy embedded CNTs and graphitic carbon layers are introduced, the $\varepsilon^{\prime}$ values of $\mathrm{Mo}_{2} \mathrm{~N} @ \mathrm{CoFe} @ \mathrm{C} / \mathrm{CNT}$ sample range from 10.2 to 5.6 with the increase in frequency, demonstrating $\mathrm{Mo}_{2} \mathrm{~N} @ \mathrm{CoFe} @ \mathrm{C} /$ CNT materials gain strong capability of energy storage and high dielectric polarization. And the $\varepsilon^{\prime \prime}$ values of $\mathrm{Mo}_{2} \mathrm{~N} @$ CoFe@C/CNT also remain high from 3.78 to 2.56, which means a powerful dielectric loss ability. This can be ascribed to the hierarchical conductive network and enhanced interfacial polarization resulting from unique core-shell structure of dielectric $\mathrm{Mo}_{2} \mathrm{~N}$ and conductive C/CNTs components. To further evaluate the dielectric loss property, the dielectric loss tangent $\delta_{\varepsilon}\left(\tan \delta_{\varepsilon}=\varepsilon^{\prime \prime} / \varepsilon^{\prime}\right)$ was calculated. It is believed that higher $\tan \delta_{\varepsilon}$ value means more electric energy of incident microwaves would be dissipated. As shown in Fig. $\mathrm{S} 9 \mathrm{a}$, the $\tan \delta_{\varepsilon}$ values of $\mathrm{Mo}_{2} \mathrm{~N} @ \mathrm{CoFe} @ \mathrm{C} / \mathrm{CNT}$ remain high, which offers the convincing evidence that the design of hierarchically core-shell structure with the combination of dielectric $\mathrm{Mo}_{2} \mathrm{~N}$ and graphitic C/CNTs components is an effective way to enhance the dielectric loss capacity. As for the real $\left(\mu^{\prime}\right)$ and imaginary $\left(\mu^{\prime \prime}\right)$ parts of permeability, the $\mu^{\prime}$ and $\mu^{\prime \prime}$ values of $\mathrm{Mo}_{2} \mathrm{~N}$ remain close to 1 and 0 due to its nonmagnetic property. Compared with $\mathrm{Mo}_{2} \mathrm{~N} @ \mathrm{Co} / \mathrm{CNT}$ samples, the $\mu^{\prime}$ and $\mu^{\prime \prime}$ of $\mathrm{Mo}_{2} \mathrm{~N} @ \mathrm{CoFe} @ \mathrm{C} / \mathrm{CNT}$ are higher because of its enhanced magnetic $\mathrm{CoFe}$ alloy component and hierarchical 3D magnetic network. Therefore, the $\mathrm{Mo}_{2} \mathrm{~N} @$ $\mathrm{CoFe} @ \mathrm{C} / \mathrm{CNT}$ material is prone to generate favorable magnetic loss capability. Based on above discussion, as-prepared $\mathrm{Mo}_{2} \mathrm{~N} @ \mathrm{CoFe} @ \mathrm{C} / \mathrm{CNT}$ composite is expected to exhibit superior MA capability originating from its both synergetic strong dielectric dissipation and magnetic loss.

The MA performance of absorbents is generally evaluated with the maximum reflection loss $(R L)$ value and effective absorption bandwidth. Figure 6 displays the 3D plots of $R L$ values on different thickness of $\mathrm{Mo}_{2} \mathrm{~N}, \mathrm{Mo}_{2} \mathrm{~N} @ \mathrm{Co} /$ $\mathrm{CNT}$ and $\mathrm{Mo}_{2} \mathrm{~N} @ \mathrm{CoFe} @ \mathrm{C} / \mathrm{CNT}$ samples. The $\mathrm{Mo}_{2} \mathrm{~N}$ rods exhibit good MA performance with the maximum $R L$ value of $-25.9 \mathrm{~dB}$ at the thickness of $4.5 \mathrm{~mm}$ (Fig. 6a) due to its high dielectric property. With the introduction of $\mathrm{Co} /$ CNTs components, the $\mathrm{Mo}_{2} \mathrm{~N} @ \mathrm{Co} / \mathrm{CNT}$ materials exhibit MA with the maximum $R L$ value of $-34.8 \mathrm{~dB}$. Significantly, as displayed in Fig. 6c, the $\mathrm{Mo}_{2} \mathrm{~N} @ \mathrm{CoFe} @ \mathrm{C} / \mathrm{CNT}$ demonstrates the best MA performance with highest maximum $R L$ value of $-53.5 \mathrm{~dB}$ at the thickness of only $2 \mathrm{~mm}$ thickness, and the effective absorption bandwidth can reach $5 \mathrm{GHz}$ (from 12 to $17 \mathrm{GHz}$ ). Moreover, while tuning the thickness from 1.5 to $5.0 \mathrm{~mm}, \mathrm{Mo}_{2} \mathrm{~N} @ \mathrm{CoFe} @ \mathrm{C} / \mathrm{CNT}$ samples still 
(a)

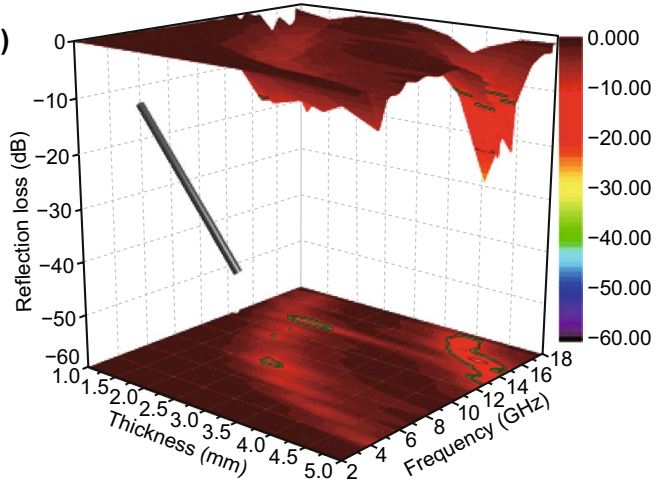

(c)

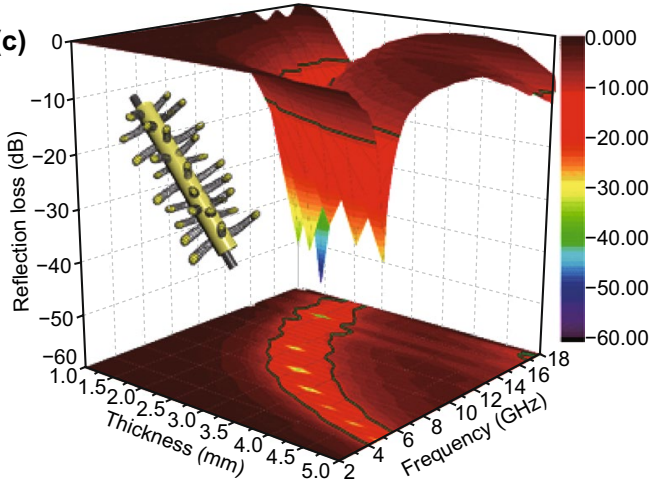

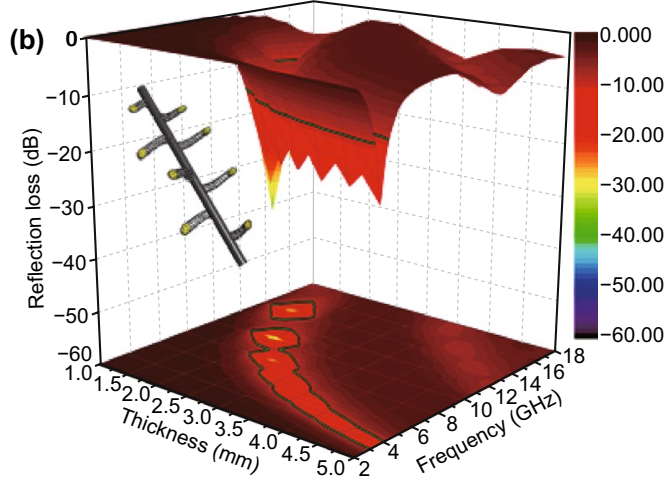

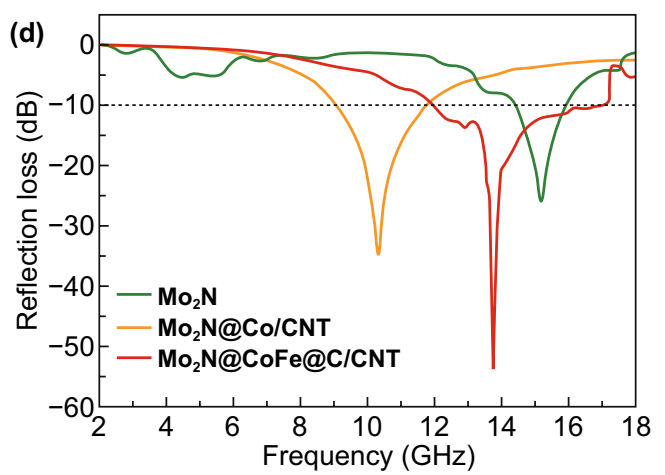

Fig. $63 \mathrm{D}$ plots of reflection loss of a $\mathrm{Mo}_{2} \mathrm{~N}$, b $\mathrm{Mo}_{2} \mathrm{~N} @ \mathrm{Co} / \mathrm{CNT}$ and $\mathbf{c} \mathrm{Mo}_{2} \mathrm{~N} @ \mathrm{CoFe} @ \mathrm{C} / \mathrm{CNT}$ samples. d Reflection loss curves at the same thickness of $2 \mathrm{~mm}$

exhibit impressive MA performance with the maximum $R L$ values all less than $-10 \mathrm{~dB}$, revealing its tunable MA ability. These encouraging results demonstrate that as-prepared $\mathrm{Mo}_{2} \mathrm{~N} @ \mathrm{CoFe} @ \mathrm{C} / \mathrm{CNT}$ composites hold excellent MA performance owing to its strong microwave energy absorption, broad effective absorption bandwidth, lower thickness and tunable absorption frequency, which is superior to those reported metal/carbon microwave absorbents (Table S1).

\subsection{Analysis of Microwave Absorption Mechanism}

Accordingly, the rational design of 3D hierarchical core-shell structure of $\mathrm{Mo}_{2} \mathrm{~N} @ \mathrm{CoFe} @ \mathrm{C} / \mathrm{CNT}$ absorber and the combination of dielectric $\mathrm{Mo}_{2} \mathrm{~N}$, conductive $\mathrm{C} /$ CNTs and magnetic CoFe alloy components contribute to the enhancement of electromagnetic storage and MA performance. Related microwave energy absorption/conversion mechanisms of MA can be illustrated as followed in detail (Fig. 7).

\subsubsection{Multiple Heterojunction Interfaces and Hierarchical Electronic Transportation Paths Boosted Dielectric Loss}

3D assembly $\mathrm{Mo}_{2} \mathrm{~N} @ \mathrm{CoFe} @ \mathrm{C} / \mathrm{CNT}$ composites possess plentiful heterojunction interfaces, which is necessary to the improvement of dielectric storage ability and polarization behaviors. Hierarchical $\mathrm{Mo}_{2} \mathrm{~N} @ \mathrm{CoFe} @ \mathrm{C} / \mathrm{CNT}$ composite is made up of dielectric $\mathrm{Mo}_{2} \mathrm{~N}$, graphitized C/CNTs and magnetic CoFe nanoparticles. In such "tubes on rods" matrix, there are at least three kinds of heterojunction interfaces, including CoFe-CNTs interfaces, graphitized carbon-CNTs interfaces and graphitized carbon- $\mathrm{Mo}_{2} \mathrm{~N}$ interfaces (Fig. 7c). Due to differences in electrical conductivity among components, free electrons gather around those contacting interfaces when applied variation of electromagnetic wave. This electronic migration/moment can produce intensive interfacial polarization and relaxation causing the conversion from electromagnetic waves energy into thermal energy. Besides, numerous carbon heteroatoms groups (such as $\mathrm{C}-\mathrm{N}$ and 


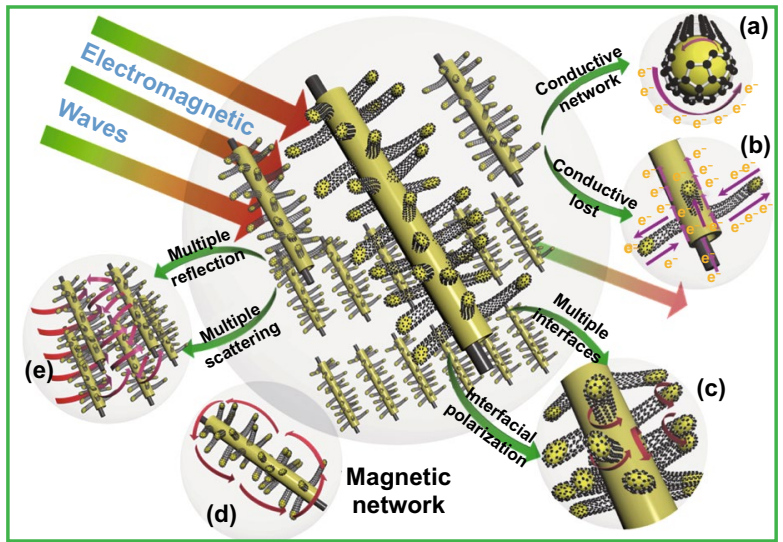

Fig. 7 The microwave absorption mechanism in the 3D hierarchical $\mathrm{Mo}_{2} \mathrm{~N} @ \mathrm{CoFe} @ \mathrm{C} / \mathrm{CNT}$ composites

C-O, Fig. 3c)in $\mathrm{Mo}_{2} \mathrm{~N} @ \mathrm{CoFe} @ \mathrm{C} / \mathrm{CNT}$ could be regarded as active dipole sites. Related dipole polarization can also improve the MA performance. Therefore, $\mathrm{Mo}_{2} \mathrm{~N} @ \mathrm{CoFe} @ \mathrm{C} /$ CNT composite exhibits higher dielectric polarization ability compared with $\mathrm{Mo}_{2} \mathrm{~N} @ \mathrm{Co} / \mathrm{CNT}$ and $\mathrm{Mo}_{2} \mathrm{~N}$ materials owing to its multiple interfaces and multicomponent. In addition, both dielectric $\mathrm{Mo}_{2} \mathrm{~N}$ rod and graphitized C/CNTs can be also considered as a conductive network. Micro-scale $\mathrm{Mo}_{2} \mathrm{~N}$ rod displays high permittivity. When graphitized $\mathrm{C} /$ $\mathrm{CNTs}$ grow on $\mathrm{Mo}_{2} \mathrm{~N}$ rod, numerous electronic transportation routes are formed between $\mathrm{C} / \mathrm{CNTs}$ and $\mathrm{Mo}_{2} \mathrm{~N}$ rod (Fig. 7a, b). This conduction transportation network facilitates enhanced conduction loss capability, which is also favorable for MA performance.

\subsubsection{Spatial Dispersed CoFe Nanoparticles Built Multi-scale Magnetic Coupling Network}

Spatial dispersed nano-scale CoFe alloy suspended within hierarchical micro-scale $\mathrm{Mo}_{2} \mathrm{~N} @ \mathrm{C} / \mathrm{CNTs}$ rod construct a multi-scale magnetic network and could significantly contribute to the boosted magnetic responding capacity (Fig. 7d). Traditionally, magnetic nanoparticles could easily aggregate together due to their magnetic nature. Metal aggregation problem can hardly be avoided in the process of pyrolyzing MOFs directly. Herein, through our ligand exchange strategy, as-synthesized $\mathrm{MoO}_{3} @$ hollow-CoFePBA structure can not only effectively reduce the aggregation of magnetic nanoparticles but also expand spatial magnetic distribution, thereby further increasing the responding scale of magnetic component in the final $\mathrm{Mo}_{2} \mathrm{~N} @ \mathrm{CoFe} @ \mathrm{C} /$
CNT composite. As-fabricated hierarchical $\mathrm{Mo}_{2} \mathrm{~N} @ \mathrm{C} / \mathrm{CNT}$ architecture provides a perfect nano/micro-matrix to support suspended CoFe nanoparticles (Figs. 4 and 5), thus forming a distributed magnetic network and strengthening magnetic permeability. The off-axis electron holography is performed to study the magnetic property of $\mathrm{CoFe}$ nanoparticles and related magnetic network in $\mathrm{Mo}_{2} \mathrm{~N} @ \mathrm{CoFe} @ \mathrm{C} / \mathrm{CNT}$ composite. As shown in Fig. $8 \mathrm{a}-\mathrm{c}$, the $\mathrm{CoFe}$ nanoparticles in the composite can radiate out high-density magnetic lines which could penetrate through the nonmagnetic graphitic $\mathrm{C} /$ CNTs and expand magnetic responding regions beyond itself size. Furthermore, the neighbored $\mathrm{CoFe}$ nanoparticle suspended within C/CNTs matrix displays magnetic coupling lines which could contribute to integral magnetic network, further strengthen magnetic dissipation capacity (Fig. 8d-f) [49]. Meanwhile, high loading and uniformly distribution of CoFe nanoparticles (Fig. 5) can also enhance the magnetic loss to promote MA performance. Therefore, compared with $\mathrm{Mo}_{2} \mathrm{~N} @ \mathrm{Co} / \mathrm{CNT}$ and other magnetic metal/carbon composites reported previously, hierarchical $\mathrm{Mo}_{2} \mathrm{~N} @ \mathrm{CoFe} @ \mathrm{C} / \mathrm{CNT}$ composite can successfully avoid magnetic metal aggregation problem and exhibit remarkable magnetic loss property.

\subsubsection{Synergic Magnetic-dielectric MA System and Multi-dimension Hierarchical Structure}

Hierarchical $\mathrm{Mo}_{2} \mathrm{~N} @ \mathrm{CoFe} @ \mathrm{C} / \mathrm{CNT}$ composites can effectively dissipate the microwave energy via dielectric dissipation and magnetic loss. The assembled composite is constructed by dielectric $\mathrm{Mo}_{2} \mathrm{~N}$ as core and spatially dispersed $\mathrm{CoFe}$ nanoparticles within C/CNTs as shell and 

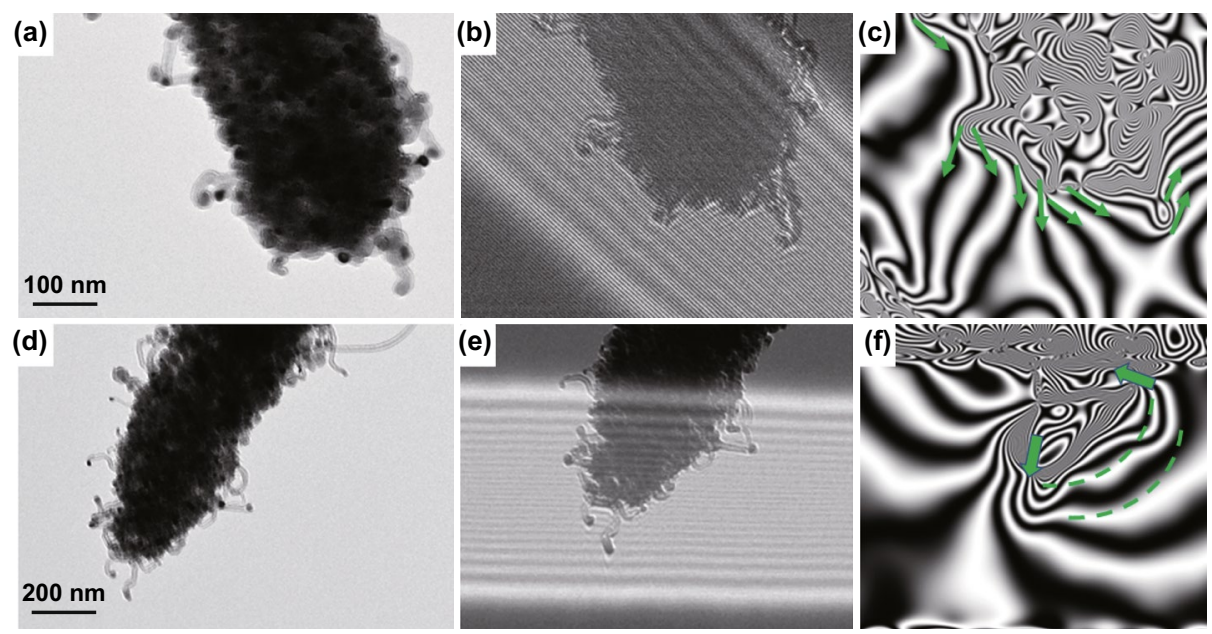

Fig. 8 a, d TEM images and b-c, e-f corresponding off-axis electron holograms of $\mathrm{Mo}_{2} \mathrm{~N} @ \mathrm{CoFe} @ \mathrm{C} / \mathrm{CNT}$ composites

thus demonstrate significantly improved MA performance resulting from both dielectric loss and magnetic loss, compared with single $\mathrm{Mo}_{2} \mathrm{~N}$ material or $\mathrm{Mo}_{2} \mathrm{~N} @ \mathrm{Co} / \mathrm{CNT}$ composite with few metal nanoparticles. Meanwhile, because of the hierarchical structure and multi-scale size, $\mathrm{Mo}_{2} \mathrm{~N} @$ $\mathrm{CoFe} @ \mathrm{C} / \mathrm{CNT}$ assembly possess unique multi-reflection and multi-scattering (Fig. 7e). Abundant 1D CNTs, microscale $\mathrm{Mo}_{2} \mathrm{~N}$ rod and 3D hierarchical core-shell structure could generate effective surface area and spacing effect. When incidence microwave permeates into this 3D architecture, expected large surface areas offer many active sites to produce multiple reflection and scattering. Such repeated reflection and scattering process of incident microwave can successfully attenuate microwave energy. Benefiting from above advantages of hierarchical structure and multi-loss mechanism, as-prepared $\mathrm{Mo}_{2} \mathrm{~N} @ \mathrm{CoFe} @ \mathrm{C} / \mathrm{CNT}$ composites exhibit superior MA performance that surpass those reported metal-carbon microwave absorbents (Table S1).

\section{Conclusion}

In conclusion, as-prepared $\mathrm{Mo}_{2} \mathrm{~N} @ \mathrm{CoFe} @ \mathrm{C} / \mathrm{CNT}$ composites exhibit superior MA performance with maximum reflection loss value of $-53.5 \mathrm{~dB}$ at the thickness of only $2 \mathrm{~mm}$ thickness and a broad effective absorption bandwidth of $5 \mathrm{GHz}$. Such 3D hierarchical core-shell structure assembled by nano-scale magnetic $\mathrm{CoFe}$ nanoparticles suspended within graphitic C/CNTs supported on micro-scale $\mathrm{Mo}_{2} \mathrm{~N}$ rod is rationally constructed via our effective ligand exchange strategy. The dielectric $\mathrm{Mo}_{2} \mathrm{~N}$ and $\mathrm{C} / \mathrm{CNTs}$ components can shape strong conductive loss and hierarchical core-shell structure offers large interfacial area to trigger polarization loss. Moreover, distributed magnetic $\mathrm{CoFe}$ nanoparticles embedded in C/CNTs matrix form multi-scale magnetic network and reinforce magnetic response capability, which is verified by the off-axis electron holography. Firmly, the MOF-based ligand exchange strategy in this work can be utilized to construct various hierarchical structure of multicomponent metal-carbon system for enhanced MA performance.

Acknowledgements This work was supported by the Ministry of Science and Technology of China (973 Project No. 2018YFA0209102) and the National Natural Science Foundation of China (11727807, 51725101, 51672050, 61790581).

Open Access This article is licensed under a Creative Commons Attribution 4.0 International License, which permits use, sharing, adaptation, distribution and reproduction in any medium or format, as long as you give appropriate credit to the original author(s) and the source, provide a link to the Creative Commons licence, and indicate if changes were made. The images or other third party material in this article are included in the article's Creative Commons licence, unless indicated otherwise in a credit line to the material. If material is not included in the article's Creative Commons licence and your intended use is not permitted by statutory regulation or exceeds the permitted use, you will need to obtain permission directly from the copyright holder. To view a copy of this licence, visit http://creativecommons.org/licenses/by/4.0/.

Electronic supplementary material The online version of this article (https://doi.org/10.1007/s40820-020-00572-5) contains supplementary material, which is available to authorized users. 


\section{References}

1. H. Lv, Z. Yang, P.L. Wang, G. Ji, J. Song et al., A voltageboosting strategy enabling a low-frequency, flexible electromagnetic wave absorption device. Adv. Mater. 30, 1706343 (2018). https://doi.org/10.1002/adma.201706343

2. M. Cao, X. Wang, W. Cao, X. Fang, B. Wen et al., Thermally driven transport and relaxation switching self-powered electromagnetic energy conversion. Small 14, 1800987 (2018). https ://doi.org/10.1002/smll.201800987

3. Y. Zhang, Y. Huang, T. Zhang, H. Chang, P. Xiao et al., Broadband and tunable high-performance microwave absorption of an ultralight and highly compressible graphene foam. Adv. Mater. 27, 2049-2053 (2015). https://doi.org/10.1002/ adma.201405788

4. M.-S. Cao, X.-X. Wang, M. Zhang, J.-C. Shu, W.-Q. Cao et al., Electromagnetic response and energy conversion for functions and devices in low-dimensional materials. Adv. Funct. Mater. 29, 1807398 (2019). https://doi.org/10.1002/adfm.201807398

5. M.-S. Cao, W.-L. Song, Z.-L. Hou, B. Wen, J. Yuan, The effects of temperature and frequency on the dielectric properties, electromagnetic interference shielding and microwaveabsorption of short carbon fiber/silica composites. Carbon 48 , 788-796 (2010). https://doi.org/10.1016/j.carbon.2009.10.028

6. X. Liu, Y. Chen, X. Cui, M. Zeng, R. Yu et al., Flexible nanocomposites with enhanced microwave absorption properties based on $\mathrm{Fe}_{3} \mathrm{O}_{4} / \mathrm{SiO}_{2}$ nanorods and polyvinylidene fluoride. J. Mater. Chem. A 3, 12197-12204 (2015). https://doi. org/10.1039/C5TA01924A

7. Z. Huang, H. Chen, Y. Huang, Z. Ge, Y. Zhou et al., Ultrabroadband wide-angle terahertz absorption properties of 3D graphene foam. Adv. Funct. Mater. 28, 1704363 (2018). https ://doi.org/10.1002/adfm.201704363

8. L. Wang, X. Li, Q. Li, Y. Zhao, R. Che, Enhanced polarization from hollow cube-like $\mathrm{ZnSnO}_{3}$ wrapped by multiwalled carbon nanotubes: as a lightweight and high-performance microwave absorber. ACS Appl. Mater. Interfaces 10, 22602-22610 (2018). https://doi.org/10.1021/acsami.8b05414

9. Y. Lian, B. Han, D. Liu, Y. Wang, H. Zhao et al., Solvent-free synthesis of ultrafine tungsten carbide nanoparticles-decorated carbon nanosheets for microwave absorption. Nano-Micro Lett. 12, 153 (2020). https://doi.org/10.1007/s40820-02000491-5

10. D. Ding, Y. Wang, X. Li, R. Qiang, P. Xu et al., Rational design of core-shell Co@C microspheres for high-performance microwave absorption. Carbon 111, 722-732 (2017). https://doi.org/10.1016/j.carbon.2016.10.059

11. L. Liu, N. He, T. Wu, P. Hu, G. Tong, $\mathrm{Co} / \mathrm{C} / \mathrm{Fe} / \mathrm{C}$ hierarchical flowers with strawberry-like surface as surface plasmon for enhanced permittivity, permeability, and microwave absorption properties. Chem. Eng. J. 355, 103-108 (2019). https:// doi.org/10.1016/j.cej.2018.08.131

12. Q. Liu, D. Zhang, T. Fan, Electromagnetic wave absorption properties of porous carbon/Co nanocomposites. Appl. Phys. Lett. 93, 013110 (2008). https://doi.org/10.1063/1.2957035
13. Z. Song, X. Liu, X. Sun, Y. Li, X. Nie et al., Alginate-templated synthesis of $\mathrm{CoFe} /$ carbon fiber composite and the effect of hierarchically porous structure on electromagnetic wave absorption performance. Carbon 151, 36-45 (2019). https:// doi.org/10.1016/j.carbon.2019.05.025

14. X. Zhang, Y. Li, R. Liu, Y. Rao, H. Rong et al., High-magnetization feco nanochains with ultrathin interfacial gaps for broadband electromagnetic wave absorption at gigahertz. ACS Appl. Mater. Interfaces 8, 3494-3498 (2016). https:// doi.org/10.1021/acsami.5b12203

15. L. Wang, B. Wen, H. Yang, Y. Qiu, N. He, Hierarchical nestlike structure of $\mathrm{Co} / \mathrm{Fe} \mathrm{MOF}$ derived $\mathrm{CoFe} @ \mathrm{C}$ composite as wide-bandwidth microwave absorber. Compos. Part A 135, 105958 (2020). https://doi.org/10.1016/j.composites a.2020.105958

16. D. Kuang, L. Hou, S. Wang, H. Luo, L. Deng et al., Largescale synthesis and outstanding microwave absorption properties of carbon nanotubes coated by extremely small FeCoC core-shell nanoparticles. Carbon 153, 52-61 (2019). https ://doi.org/10.1016/j.carbon.2019.06.105

17. F. Wang, N. Wang, X. Han, D. Liu, Y. Wang et al., Coreshell FeCo@carbon nanoparticles encapsulated in polydopamine-derived carbon nanocages for efficient microwave absorption. Carbon 145, 701-711 (2019). https://doi. org/10.1016/j.carbon.2019.01.082

18. D. Liu, Y. Du, P. Xu, N. Liu, Y. Wang et al., Waxberry-like hierarchical Ni@C microspheres with high-performance microwave absorption. J. Mater. Chem. C 7, 5037-5046 (2019). https://doi.org/10.1039/C9TC00771G

19. F. Wen, F. Zhang, Z. Liu, Investigation on microwave absorption properties for multiwalled carbon nanotubes $/ \mathrm{Fe} /$ $\mathrm{Co} / \mathrm{Ni}$ nanopowders as lightweight absorbers. J. Phys. Chem. C 115, 14025-14030 (2011). https://doi.org/10.1021/jp202 $078 \mathrm{p}$

20. J. Xiang, J. Li, X. Zhang, Q. Ye, J. Xu et al., Magnetic carbon nanofibers containing uniformly dispersed $\mathrm{Fe} / \mathrm{Co} / \mathrm{Ni}$ nanoparticles as stable and high-performance electromagnetic wave absorbers. J. Mater. Chem. A 2, 16905-16914 (2014). https:// doi.org/10.1039/C4TA03732D

21. X. Li, M. Zhang, W. You, K. Pei, Q. Zeng et al., Magnetized mxene microspheres with multiscale magnetic coupling and enhanced polarized interfaces for distinct microwave absorption via a spray-drying method. ACS Appl. Mater. Interfaces 12, 18138-18147 (2020). https://doi.org/10.1021/acsami.0c00935

22. K. Zhang, J. Li, F. Wu, M. Sun, Y. Xia et al., Sandwich $\mathrm{CoFe}_{2} \mathrm{O}_{4} / \mathrm{rGO} / \mathrm{CoFe}_{2} \mathrm{O}_{4}$ nanostructures for high-performance electromagnetic absorption. ACS Appl. Nano Mater. 2, 315324 (2019). https://doi.org/10.1021/acsanm.8b01927

23. G. Tong, F. Liu, W. Wu, F. Du, J. Guan, Rambutan-like ni/ mwcnt heterostructures: easy synthesis, formation mechanism, and controlled static magnetic and microwave electromagnetic characteristics. J. Mater. Chem. A 2, 7373-7382 (2014). https ://doi.org/10.1039/C4TA00117F

24. Z. Wang, J. Wang, Y. Li, R. Liu, Y. Zhang et al., Multi-interfacial Co@CoN $@ \mathrm{C}(\mathrm{N})$ nanocapsules with nitrogen substitutions in graphitic shells for improving microwave absorption 
properties. J. Alloys Compd. 736, 51-56 (2018). https://doi. org/10.1016/j.jallcom.2017.11.069

25. R.C. Che, L.-M. Peng, X.F. Duan, Q. Chen, X.L. Liang, Microwave absorption enhancement and complex permittivity and permeability of Fe encapsulated within carbon nanotubes. Adv. Mater. 16, 401-405 (2004). https://doi.org/10.1002/ adma.200306460

26. R. Shu, W. Li, Y. Wu, J. Zhang, G. Zhang, Nitrogen-doped Co-C/MWCNTs nanocomposites derived from bimetallic metal-organic frameworks for electromagnetic wave absorption in the X-band. Chem. Eng. J. 362, 513-524 (2019). https ://doi.org/10.1016/j.cej.2019.01.090

27. G. Wang, Z. Gao, G. Wan, S. Lin, P. Yang et al., High densities of magnetic nanoparticles supported on graphene fabricated by atomic layer deposition and their use as efficient synergistic microwave absorbers. Nano Res. 7, 704-716 (2014). https:// doi.org/10.1007/s12274-014-0432-0

28. Y. Li, R. Liu, X. Pang, X. Zhao, Y. Zhang et al., Fe@C nanocapsules with substitutional sulfur heteroatoms in graphitic shells for improving microwave absorption at gigahertz frequencies. Carbon 126, 372-381 (2018). https://doi. org/10.1016/j.carbon.2017.10.040

29. J. He, D. Shan, S. Yan, H. Luo, C. Cao, Y. Peng, Magnetic FeCo nanoparticles-decorated $\mathrm{Ti}_{3} \mathrm{C}_{2}$ Mxene with enhanced microwave absorption performance. J. Magn. Magn. Mater. 492, 165639 (2019). https://doi.org/10.1016/j. jmmm.2019.165639

30. H. Luo, W. Feng, C. Liao, L. Deng, S. Liu et al., Peaked dielectric responses in $\mathrm{Ti}_{3} \mathrm{C}_{2}$ Mxene nanosheets enabled composites with efficient microwave absorption. J. Appl. Phys. 123, 104103 (2018). https://doi.org/10.1063/1.5008323

31. J. Li, S. Yang, P. Jiao, Q. Peng, W. Yin et al., Three-dimensional macroassembly of hybrid C@CoFe nanoparticles/ reduced graphene oxide nanosheets towards multifunctional foam. Carbon 157, 427-436 (2020). https://doi.org/10.1016/j. carbon.2019.10.074

32. M. Ning, J. Li, B. Kuang, C. Wang, D. Su, Y. Zhao, H. Jin, M. Cao, One-step fabrication of n-doped cnts encapsulating $\mathrm{M}$ nanoparticles $(\mathrm{M}=\mathrm{Fe} \mathrm{Co}, \mathrm{Ni})$ for efficient microwave absorption. Appl. Surf. Sci. 447, 244-253 (2018). https://doi. org/10.1016/j.apsusc.2018.03.242

33. G.J.D.A.A. Soler-Illia, C. Sanchez, B. Lebeau, J. Patarin, Chemical strategies to design textured materials: from microporous and mesoporous oxides to nanonetworks and hierarchical structures. Chem. Rev. 102, 4093-4138 (2002)

34. Z. Xiang, J. Xiong, B. Deng, E. Cui, L. Yu et al., Rational design of $2 \mathrm{~d}$ hierarchically laminated $\mathrm{Fe}_{3} \mathrm{O}_{4} @$ nanoporous carbon@rGO nanocomposites with strong magnetic coupling for excellent electromagnetic absorption applications. J. Mater. Chem. C 8, 2123-2134 (2020). https://doi.org/10.1039/C9TC0 6526A

35. N. Yang, Z.-X. Luo, S.-C. Chen, G. Wu, Y.-Z. Wang, $\mathrm{Fe}_{3} \mathrm{O}_{4}$ nanoparticle/n-doped carbon hierarchically hollow microspheres for broadband and high-performance microwave absorption at an ultralow filler loading. ACS Appl. Mater.
Interfaces 12, 18952-18963 (2020). https://doi.org/10.1021/ acsami.0c04185

36. X. Yuan, R. Wang, W. Huang, L. Kong, S. Guo et al., Morphology design of co-electrospinning $\mathrm{MnO}-\mathrm{VN} / \mathrm{C}$ nanofibers for enhancing the microwave absorption performances. ACS Appl. Mater. Interfaces 12, 13208-13216 (2020). https://doi. org/10.1021/acsami.9b23310

37. W. You, H. Bi, W. She, Y. Zhang, R. Che, Dipolar-distribution cavity $\gamma-\mathrm{Fe}_{2} \mathrm{O}_{3} @ \mathrm{C} @ \alpha-\mathrm{MnO}_{2}$ nanospindle with broadened microwave absorption bandwidth by chemically etching. Small 13, 1602779 (2017). https://doi.org/10.1002/smll.201602779

38. H. Lv, G. Ji, W. Liu, H. Zhang, Y. Du, Achieving hierarchical hollow carbon@Fe@ $\mathrm{Fe}_{3} \mathrm{O}_{4}$ nanospheres with superior microwave absorption properties and lightweight features. J. Mater. Chem. C 3, 10232-10241 (2015). https://doi.org/10.1039/ C5TC02512E

39. Z. Wu, D. Tan, K. Tian, W. Hu, J. Wang et al., Facile preparation of core-shell $\mathrm{Fe}_{3} \mathrm{O}_{4} @$ polypyrrole composites with superior electromagnetic wave absorption properties. J. Phys. Chem. C 121, 15784-15792 (2017). https://doi.org/10.1021/ acs.jpcc. $7 \mathrm{~b} 04230$

40. R. Qiang, Y. Du, H. Zhao, Y. Wang, C. Tian et al., Metal organic framework-derived $\mathrm{Fe} / \mathrm{C}$ nanocubes toward efficient microwave absorption. J. Mater. Chem. A 3, 13426-13434 (2015). https://doi.org/10.1039/C5TA01457C

41. T. Wu, Y. Liu, X. Zeng, T. Cui, Y. Zhao et al., Facile hydrothermal synthesis of $\mathrm{Fe}_{3} \mathrm{O}_{4} / \mathrm{C}$ core-shell nanorings for efficient low-frequency microwave absorption. ACS Appl. Mater. Interfaces 8, 7370-7380 (2016). https://doi.org/10.1021/acsam i.6b00264

42. T. Liu, Y. Pang, M. Zhu, S. Kobayashi, Microporous Co@CoO nanoparticles with superior microwave absorption properties. Nanoscale 6, 2447-2454 (2014). https://doi.org/10.1039/ C3NR05238A

43. C. Chen, Q. Liu, H. Bi, W. You, W. She et al., Fabrication of hierarchical $\mathrm{TiO}_{2}$ coated $\mathrm{Co}_{20} \mathrm{Ni}_{80}$ particles with tunable core sizes as high-performance wide-band microwave absorbers. Phys. Chem. Chem. Phys. 18, 26712-26718 (2016). https:// doi.org/10.1039/C6CP04081K

44. M. Qiao, X. Lei, Y. Ma, L. Tian, X. He et al., Application of yolk-shell $\mathrm{Fe}_{3} \mathrm{O}_{4} @ \mathrm{~N}$-doped carbon nanochains as highly effective microwave-absorption material. Nano Res. 11, 15001519 (2018). https://doi.org/10.1007/s12274-017-1767-0

45. X. Shi, W. You, Y. Zhao, X. Li, Z. Shao et al., Multi-scale magnetic coupling of Fe@ $\mathrm{SiO}_{2} @ \mathrm{C}-\mathrm{Ni}$ yolk@triple-shell microspheres for broadband microwave absorption. Nanoscale 11, 17270-17276 (2019). https://doi.org/10.1039/C9NR0 6629B

46. Q. Liu, Q.Cao, H. Bi, C. Liang, K. Yuan et al., CoNi@SiO @ $\mathrm{TiO}_{2}$ and $\mathrm{CoNi} @$ air@ $\mathrm{TiO}_{2}$ microspheres with strong wideband microwave absorption. Adv. Mater. 28, 486-490 (2016). https://doi.org/10.1002/adma.201503149

47. X. Xu, F. Ran, Z. Fan, H. Lai, Z. Cheng et al., Cactus-inspired bimetallic metal-organic framework-derived 1D-2D hierarchical $\mathrm{Co} / \mathrm{N}$-decorated carbon architecture toward enhanced electromagnetic wave absorbing performance. ACS Appl. Mater. 
Interfaces 11, 13564-13573 (2019). https://doi.org/10.1021/ acsami.9b00356

48. N. He, M. Liu, J. Qi, J. Tong, W. Sao et al., Plasmon resonance strategy to enhance permittivity and microwave absorbing performance of $\mathrm{Cu} / \mathrm{C}$ core-shell nanowires. Chem. Eng. J. 378, 122160 (2019). https://doi.org/10.1016/j.cej.2019.122160

49. Z. Wu, K. Pei, L. Xing, X. Yu, W. You, R. Che, Enhanced microwave absorption performance from magnetic coupling of magnetic nanoparticles suspended within hierarchically tubular composite. Adv. Funct. Mater. 29, 1901448 (2019). https://doi.org/10.1002/adfm.201901448

50. H. Furukawa, K.E. Cordova, M. O'Keeffe, O.M. Yaghi, The chemistry and applications of metal-organic frameworks. Science 341, 1230444 (2013). https://doi.org/10.1126/scien ce. 1230444

51. H. Zhang, J. Nai, L. Yu, X.W. Lou, Metal-organic-framework-based materials as platforms for renewable energy and environmental applications. Joule 1, 77-107 (2017). https:// doi.org/10.1016/j.joule.2017.08.008

52. Z. Zhao, J. Ding, R. Zhu, H. Pang, The synthesis and electrochemical applications of core-shell MOFs and their derivatives. J. Mater. Chem. A 7, 15519-15540 (2019). https://doi. org/10.1039/C9TA03833G

53. C. Xu, Z. Lin, D. Zhao, Y. Sun, Y. Zhong et al., Facile in situ fabrication of Co nanoparticles embedded in 3D N-enriched mesoporous carbon foam electrocatalyst with enhanced activity and stability toward oxygen reduction reaction. J. Mater. Sci. 54, 5412-5423 (2019). https://doi.org/10.1007/ s10853-018-03255-0

54. W. Liu, L. Liu, Z. Yang, J. Xu, Y. Hou et al., A versatile route toward the electromagnetic functionalization of metalorganic framework-derived three-dimensional nanoporous carbon composites. ACS Appl. Mater. Interfaces 10, 89658975 (2018). https://doi.org/10.1021/acsami.8b00320

55. W. Liu, Q. Shao, G. Ji, X. Liang, Y. Cheng et al., Metalorganic-frameworks derived porous carbon-wrapped Ni composites with optimized impedance matching as excellent lightweight electromagnetic wave absorber. Chem. Eng. J. 313, 734-744 (2017). https://doi.org/10.1016/j.cej.2016.12.117

56. M. Huang, L. Wang, K. Pei, W. You, X. Yu et al., Multidimension-controllable synthesis of MOF-derived Co@N-doped carbon composite with magnetic-dielectric synergy toward strong microwave absorption. Small 16, 2000158 (2020). https ://doi.org/10.1002/smll.202000158

57. L. Wang, X. Yu, X. Li, J. Zhang, M. Wang et al., MOFderived yolk-shell Ni@C@ZnO schottky contact structure for enhanced microwave absorption. Chem. Eng. J. 383, 123099 (2020). https://doi.org/10.1016/j.cej.2019.123099

58. Y. Wang, H. Wang, J. Ye, L. Shi, X. Feng, Magnetic CoFe alloy@C nanocomposites derived from $\mathrm{ZnCo-MOF}$ for electromagnetic wave absorption. Chem. Eng. J. 383, 123096 (2020). https://doi.org/10.1016/j.cej.2019.123096

59. J.-C. Shu, X.-Y. Yang, X.-R. Zhang, X.-Y. Huang, M.-S. Cao et al., Tailoring MOF-based materials to tune electromagnetic property for great microwave absorbers and devices.
Carbon 162, 157-171 (2020). https://doi.org/10.1016/j.carbo n.2020.02.047

60. L. Wang, M. Huang, X. Yu, W. You, J. Zhang et al., MOFderived $\mathrm{Ni}_{1-\mathrm{x}} \mathrm{Co}_{\mathrm{x}} @$ carbon with tunable nano-microstructure as lightweight and highly efficient electromagnetic wave absorber. Nano-Micro Lett. 12, 150 (2020). https://doi. org/10.1007/s40820-020-00488-0

61. W. Liu, S. Tan, Z. Yang, G. Ji, Enhanced low-frequency electromagnetic properties of MOF-derived cobalt through interface design. ACS Appl. Mater. Interfaces 10, 31610-31622 (2018). https://doi.org/10.1021/acsami.8b10685

62. Z. Li, X. Han, Y. Ma, D. Liu, Y. Wang et al., MOFs-derived hollow $\mathrm{Co} / \mathrm{C}$ microspheres with enhanced microwave absorption performance. ACS Sustain. Chem. Eng. 6, 8904-8913 (2018). https://doi.org/10.1021/acssuschemeng.8b01270

63. S. Wang, Y. Xu, R. Fu, H. Zhu, Q. Jiao et al., Rational construction of hierarchically porous $\mathrm{Fe}-\mathrm{Co} / \mathrm{N}$-doped carbon/ rGO composites for broadband microwave absorption. NanoMicro Lett. 11, 76 (2019). https://doi.org/10.1007/s4082 0-019-0307-8

64. C. Xu, Q. Li, J. Shen, Z. Yuan, J. Ning et al., A facile sequential ion exchange strategy to synthesize $\mathrm{CoSe}_{2} / \mathrm{FeSe}_{2}$ doubleshelled hollow nanocuboids for the highly active and stable oxygen evolution reaction. Nanoscale 11, 10738-10745 (2019). https://doi.org/10.1039/C9NR02599E

65. Y.-Y. Chen, Y. Zhang, W.-J. Jiang, X. Zhang, Z. Dai et al., Pomegranate-like N, P-doped Mo2C@C nanospheres as highly active electrocatalysts for alkaline hydrogen evolution. ACS Nano 10, 8851-8860 (2016). https://doi.org/10.1021/ acsnano.6b04725

66. G. Ma, Z. Wang, B. Gao, T. Ding, Q. Zhong et al., Multilayered paper-like electrodes composed of alternating stacked mesoporous $\mathrm{Mo}_{2} \mathrm{~N}$ nanobelts and reduced graphene oxide for flexible all-solid-state supercapacitors. J. Mater. Chem. A 3, 14617-14624 (2015). https://doi.org/10.1039/C5TA02851E

67. B. Guo, K. Yu, H. Li, H. Song, Y. Zhang et al., Hollow structured micro/nano $\mathrm{MoS}_{2}$ spheres for high electrocatalytic activity hydrogen evolution reaction. ACS Appl. Mater. Interfaces 8, 5517-5525 (2016). https://doi.org/10.1021/acsami.5b10252

68. Q. Liu, Z. Xue, B. Jia, Q. Liu, K. Liu et al., Hierarchical nanorods of $\mathrm{MoS}_{2} / \mathrm{MoP}$ heterojunction for efficient electrocatalytic hydrogen evolution reaction. Small 16, 2002482 (2020). https://doi.org/10.1002/smll.202002482

69. X. Shi, A. Wu, H. Yan, L. Zhang, C. Tian et al., A "MOFs plus MOFs" strategy toward $\mathrm{Co}-\mathrm{Mo}_{2} \mathrm{~N}$ tubes for efficient electrocatalytic overall water splitting. J. Mater. Chem. A 6, 20100-20109 (2018). https://doi.org/10.1039/C8TA07906D

70. C. Huang, Q. Ruan, H. Song, Y. Luo, H. Bai et al., Vertical kinetically oriented $\mathrm{MoS}_{2}-\mathrm{Mo}_{2} \mathrm{~N}$ heterostructures on carbon cloth: a highly efficient hydrogen evolution electrocatalyst. Sustain. Energ. Fuels 4, 2201-2207 (2020). https://doi. org/10.1039/D0SE00144A

71. B. Cao, G.M. Veith, J.C. Neuefeind, R.R. Adzic, P.G. Khalifah, Mixed close-packed cobalt molybdenum nitrides as non-noble metal electrocatalysts for the hydrogen evolution 
reaction. J. Am. Chem. Soc. 135, 19186-19192 (2013). https ://doi.org/10.1021/ja4081056

72. S. Yang, Y. Zhang, S. Wang, J. Shi, X. Liu et al., Rational construction of $\mathrm{MoS}_{2} / \mathrm{Mo}_{2} \mathrm{~N} / \mathrm{C}$ hierarchical porous tubular nanostructures for enhanced lithium storage. J. Mater. Chem. A 7, 23886-23894 (2019). https://doi.org/10.1039/C9TA04516C

73. C. Wu, Z. Chen, M. Wang, X. Cao, Y. Zhang et al., Confining tiny $\mathrm{MoO}_{2}$ clusters into reduced graphene oxide for highly efficient low frequency microwave absorption. Small 16, 2001686 (2020). https://doi.org/10.1002/smll.202001686

74. Y. Wang, X. Li, X. Han, P. Xu, L. Cui et al., Ternary $\mathrm{Mo}_{2} \mathrm{C} /$ $\mathrm{Co} / \mathrm{C}$ composites with enhanced electromagnetic waves absorption. Chem. Eng. J. 387, 124159 (2020). https://doi. org/10.1016/j.cej.2020.124159

75. M.-Q. Ning, M.-M. Lu, J.-B. Li, Z. Chen, Y.-K. Dou et al., Two-dimensional nanosheets of $\mathrm{MoS}_{2}$ : a promising material with high dielectric properties and microwave absorption performance. Nanoscale 7, 15734-15740 (2015). https://doi. org/10.1039/C5NR04670J

76. L. Liu, Y. Wang, F. Yan, C. Zhu, B. Geng et al., Cobalt-encapsulated nitrogen-doped carbon nanotube arrays for flexible zinc-air batteries. Small Methods 4, 1900571 (2020). https:// doi.org/10.1002/smtd.201900571
77. Y. Lu, X. Zhang, X. Mao, Y. Huang, Engineering FeCo alloy@N-doped carbon layers by directly pyrolyzing prussian blue analogue: new peroxidase mimetic for chemiluminescence glucose biosensing. J. Mater. Chem. B 7, 4661-4668 (2019). https://doi.org/10.1039/C9TB00797K

78. C.-Y. Su, H. Cheng, W. Li, Z.-Q. Liu, N. Li et al., Atomic modulation of FeCo-nitrogen-carbon bifunctional oxygen electrodes for rechargeable and flexible all-solid-state zincair battery. Adv. Energy Mater. 7, 1602420 (2017). https://doi. org/10.1002/aenm.201602420

79. L. Yang, S. Feng, G. Xu, B. Wei, L. Zhang, Electrospun MOF-based FeCo nanoparticles embedded in nitrogen-doped mesoporous carbon nanofibers as an efficient bifunctional catalyst for oxygen reduction and oxygen evolution reactions in zinc-air batteries. ACS Sustain. Chem. Eng. 7, 5462-5475 (2019). https://doi.org/10.1021/acssuschemeng.8b06624

80. X. Li, W. You, L. Wang, J. Liu, Z. Wu et al., Self-assemblymagnetized mxene avoid dual-agglomeration with enhanced interfaces for strong microwave absorption through a tunable electromagnetic property. ACS Appl. Mater. Interfaces 11, 44536-44544 (2019). https://doi.org/10.1021/acsami.9b11861 